\title{
Experience with Mentoring and Directing Graduate Student Research at a Distance in a Mechanical Engineering Program
}

Dr. Vincent Capece, University of Kentucky

Vincent R. Capece is an Associate Professor of Mechanical Engineering. Dr. Capece received his B.S. degree in Mechanical Engineering from Tennessee Technological University in 1980, M.S. in Mechanical Engineering from MIT in 1982, and Ph.D. from Purdue University in 1987.

\section{Dr. John R. Baker, University of Kentucky}

John R. Baker is an Associate Professor of Mechanical Engineering at the University of Kentucky Extended Campus Program in Paducah, KY. He received his B.S., M.S., and Ph.D. in Mechanical Engineering from the University of Kentucky in Lexington, KY. After obtaining his B.S., he spent three years working in the Plastics Division of Eastman Chemical Products, Inc. He entered his current position in July 2000 . 


\title{
Experience with Mentoring and Directing Graduate Student Research at a Distance in a Mechanical Engineering Program
}

\begin{abstract}
The advising of graduate student research projects from a distance requires both planning and flexibility from both the graduate student and the advisor. This paper provides an overview of the experience of the authors in the development of research programs in mechanical engineering in a distance education setting from an extended campus.
\end{abstract}

\section{Introduction and Background}

With the widespread availability of the internet and increased ownership of computers, it is natural that distance education would develop that uses the online environment. Currently most public and private universities and colleges have online courses. Moreover, there are for-profit universities with online degree programs. The online courses have evolved to include advanced degree programs involving a research component that could include a student thesis (see for example References 1-5). A key part of these advanced degree programs is mentoring of the distance graduate students so they can successfully complete their research efforts.

The development of an MS distance learning degree program in engineering with a biomedical specialization is discussed by Griffin et al. ${ }^{1}$ to provide an advanced degree opportunity for engineers working in California. They found that communication concerning the requirements for a thesis and to provide motivation for students to finish their theses were issues for distance students. Additional time requirements for academic advising were also found to be necessary. The communication challenge has also been highlighted by Biezael and $\mathrm{Tso}^{2}$ in a distance graduate program for students at Vandenberg Air Force Base. Emails, phone calls, scanned files, etc. that involved faculty and student interactions were found to be 'far from ideal'. Bumblauskas $^{4}$ presents a brief review of distance learning trends and experiences from a graduate student that has been an on- and off-campus student. An observation that was mentioned on the importance of face-to-face communication indicates the usefulness of the development of Internet teleconferencing to provide video conferencing tools for remote collaborations real-time. An internationally cooperative program presented by Kassegne ${ }^{5}$ discusses the supervision of graduate students in Ethiopia from the United States. Student surveys mentioned misunderstandings that occurred with written communications and the benefits the students received from interacting with advisors at a more focused technical level. One of the difficulties encountered was the reliability of Internet access.

In this paper, an overview of 12 years of mentoring and directing graduate students in mechanical engineering at the University of Kentucky in a distance education setting is presented. A unique aspect of the current paper is that the graduate students primarily reside on 
the main campus in Lexington, Kentucky while the faculty members are located on an extended campus located in Paducah, Kentucky. This paper presents strategies used to help students overcome communication issues with remotely located faculty members, the use of distance communication technology, and experience managing distance experimental programs, which were not covered in the references highlighted. To begin, a short summary of the college of engineering extended campus program in mechanical engineering will be discussed. A more complete description of this program can be found in Reference 6.

\section{Extended Campus Program}

The University of Kentucky, College of Engineering has established mechanical and chemical undergraduate engineering programs in western Kentucky. These extended campus programs are unique because they are located on a community college campus over 250 miles from the main Lexington campus, and they are the direct responsibility of the Lexington campus College of Engineering dean. These engineering programs have received separate ABET accreditation because of the differences in location, facilities, administration, and support services from the engineering programs in Lexington.

All Paducah faculty positions, with the exception of the former director, are special-title series. These positions are primarily upper division nine-month teaching appointments. However, due to the nature of the Paducah program, these appointments involve additional assignments, including student recruitment, undergraduate laboratory development, and professional development. The traditional responsibilities involving instruction, academic advisement, and university service also apply. Because of these unique responsibilities and the limited access to graduate students, the expectation for research productivity is less than for the faculty on the Lexington campus. However, the faculty members are expected to develop a research program and advise graduate students.

Since the Paducah programs are undergraduate degree programs, graduate student classes (beyond dual level) are not available. It is rare for graduate students that have completed their graduate courses in Lexington to relocate to the Paducah campus to complete their research; it is more common for the graduate students to remain in Lexington for their entire graduate student program. This requires the faculty members in Paducah to use distance communication technology to advise and direct the research efforts of the graduate students located in Lexington.

\section{Communication}

The most important part of mentoring and directing graduate student research is the ability to effectively communicate from Paducah with the graduate students based on the main campus in Lexington. In a situation where the graduate students and faculty reside on the same campus, communication typically occurs in two major forms. Normally there will be the formal meetings where research and course advising occur. The second form of interaction, which in many cases is the most important to keep research moving forward in a timely fashion, are those frequent 
five minute interactions. This is where those 'quick questions' are resolved. The regular meeting type of interaction can be dealt with, although imperfectly, using distance communication techniques, as will be discussed below. It is the five minute question communication that creates the hardest challenge for distance graduate students and their advisors.

The most obvious and frequently used communication technique has been email. There are two advantages to using email. First, using email documents all the interactions with the graduate student. This is advantageous in that the student can often refer back to the email to clear up any misunderstandings that often occur with verbal communication. Secondly, email can be sent independent of location.

Email communication also has some disadvantages. It can take a considerable amount of time to formulate the email. Unlike verbal interactions, email communications are similar to formal writing; hence, there are concerns with spelling and grammar that do not arise during a verbal interaction. In addition, there can be a considerable delay in responding to email queries partly due to the time necessary to compose written answers to the questions, and also partly due to the lack of constant monitoring of email. Due to occupation with other duties, a faculty member may have time for a quick verbal interaction when a student stops by the office, but may not have time to compose an email. In email communications, follow up questions require additional rounds of emails. In a verbal communication, there is opportunity for follow up questions to reduce the chances of misunderstandings. Furthermore, in engineering mathematical derivations are often involved. Standard email interfaces do not handle mathematical equations adequately. To overcome this difficulty, word processors and scanned versions of handwritten notes have been used for complex equations and questions. For rapid feedback, in many instances the document from the word processor is converted to an Adobe Portable Document File (PDF). The PDF can be printed and handwritten notes added. The annotated PDF can then be scanned and returned. A benefit of using the word processor approach is that the graduate student can have a significant portion of the mathematical development in publication form for paper publications or thesis.

With the invention of smart phones it has been found that some students feel more comfortable sending text messages to ask 'quick' questions. If appropriate, a text message response can be returned or it might lead to an email, phone call, or other distance communication interaction with the student.

Over the years a number of different communication methods/systems have been used beyond traditional phone conferences for formal research meetings. Initially Interactive Television (ITV) was primarily used. ITV, which uses compressed video over the internet, is used by the University of Kentucky for distance education classes. Hence, it is a university maintained system that can be used to schedule formal research meetings. The system provides an overhead-type projector (Elmo) at each location for diagramming and writing mathematical 
relationships much like would be done on a pad of paper or whiteboard in an office setting. The difficulties with this approach include scheduling meeting times based on advisor-student availability and working around the times the ITV system is being used for other distance education courses, and the finite amount of time for the research meeting. There have been times when the meeting would abruptly end since the allotted time period had expired. Another disadvantage to the use of ITV technology for standard faculty/graduate student interactions is the time expenditure for the ITV technicians. So, while difficult to quantify, it can be assumed there is some cost for the university associated with such meetings.

Initially, ITV was supplemented with videoconferencing software. However, with campus hardware upgrades, videoconferencing is now the preferred meeting method for both formal research meetings along with impromptu meetings. This method removes the scheduling conflict with ITV availability and permits flexible meeting lengths. The videoconferencing software packages most frequently used are Skype and Adobe Connect Pro. Adobe Connect Pro includes a whiteboard that can be written on by both parties in the conference as well as remote desktop control. Remote desktop control is particularly useful when demonstrating or answering questions concerning software that is being used in research projects. As the name implies, videoconferencing allows the use of webcams. Typically only the microphones in the webcams are used to reduce bandwidth demands. The greatest advantage to using Adobe Connect Pro is the ability for the faculty member and the student to simultaneously use the whiteboard and has been the most effective method used thus far.

To keep the lines of communication open, weekly meetings are generally scheduled at the beginning of the semester. These meetings cover research projects, course work, and general advising and mentoring. In many instances the students are requested to send an email highlighting their research progress and any outstanding questions or topics that need to be discussed before the scheduled videoconference. This approach has been found to increase the effectiveness of the weekly meetings.

Meetings with the graduate students are supplemented through faculty travel from the Paducah campus to the Lexington campus, which are typically done on a monthly basis. While the four plus hours of driving time is time consuming for the faculty member, it is beneficial for the student and faculty member and has been found to increase productivity. Student travel to meet with the faculty member in Paducah is not common due to the distance and financial constraints unless the student's primary residence is in Paducah.

An additional communication method that has been used for setting up software and/or to demonstrate software usage has been faculty-produced videos using Camtasia Studio. These videos are sent to individual students as needed and are kept in a central repository by the faculty for future distribution when necessary. These videos, while initially time consuming to make, are beneficial when multiple students can benefit from the same information over time. 
Even with these mechanisms it becomes abundantly clear that effective communication with distance graduate students requires a significant commitment for the advisor and student to ensure that research and advising are done in a timely manner. For this system to work, you truly cannot take the attitude that "you will do it tomorrow." While communication technologies have advanced dramatically in recent years, none of the available methods for distance communication are $100 \%$ reliable at all times. An internet outage will prevent the use of ITV, videoconferencing, and on the Paducah campus, telephone communication using office phones. There can be problems along the ITV transmission path outside the campus that prevents ITV meetings. Other issues can occur, such as videoconferencing software unexpectedly requiring at least one meeting participant to download updates at the time of the meeting which can interrupt the communication process. While there are IT personnel available for major computer maintenance issues, day-to-day maintenance of computer systems, such as software updates, are largely the responsibility of the faculty and graduate students who use the computers. Telephone communications can also be fraught with problems. Graduate students on the Lexington campus often rely on their personal cell phones which can have poor reception even today. It is obvious that advising a distance graduate student takes more time and effort because of the pre-planning that is necessary, and even then can be interrupted by the various problems mentioned above.

\section{Research}

When advising graduate students from a distance, serious consideration needs to be made at the onset of a student's graduate program regarding the nature of the research project. The challenges outlined above apply regardless of whether the student's research is primarily computational, primarily experimental, or a combination. The most success has been with computational oriented projects. Experimental projects are still a work in progress.

In the case of computational research projects using video conferencing software with screen sharing capabilities, productive discussions are feasible with the student and advisor viewing the same information on their respective computer monitors. Experience has shown that this is not as effective or efficient as meeting in-person in the same room, but it is workable.

There are additional challenges when the student's project is experimental, and the type of challenges encountered depends on the location where the experiment is being conducted. The authors have conducted experimental programs using equipment that is unique to the campus located in Paducah. This requires the graduate students to travel to Paducah to perform the experiments and is only feasible when a student can spend some significant time on the campus in Paducah, which is rare. Generally, the organization of the experiment in terms of facility setup, facility alterations, and securing the equipment has been the responsibility of the faculty advisor. Undergraduate students can provide support in these efforts, but their experience and availability are limiting factors in their overall contribution. Furthermore, to maximize the graduate student's productivity, the faculty advisor must be present and available during the 
actual experiment in case of any problems that may occur. For the faculty member this ends up being a time consuming effort which can impact productivity and needs to be considered.

Experimental projects located in Lexington have highlighted additional issues that must be considered. The faculty advisor should very carefully consider the student's experience level, communication skills, and the resources available. When unexpected results are obtained, it can be very difficult to ascertain whether a students' experimental approach is reasonable without being able to accompany the student to the lab and review the experimental set-up and the experimental procedures. In some cases, students have made photographs of a set-up and attempted to ask questions via distance communication methods regarding the experimental setup and procedure. This has proven to be a very inefficient method of addressing problems. Also, experimental efforts often involve multiple students. In the case of faculty based at Paducah advising graduate students in Lexington, involvement of an undergraduate researcher in Paducah is only workable in rare circumstances. Borrowing equipment from the campus in Paducah for use by a graduate student in Lexington, or borrowing equipment from the campus in Lexington for use by an undergraduate researcher in Paducah, is not usually realistic because of the distance between the two campuses. Some efforts have been made in transferring equipment, but it seems to be so inefficient that it is advisable to avoid this process. It is usually best to structure projects in a way that this is not necessary.

While distance advising of graduate students on experimental projects can be workable in some cases, such as when it is feasible for a student to spend some significant time on the campus in Paducah, faculty should be cautious in embarking on such an effort. Of course, this can be a limiting factor in graduate student recruitment for faculty based in Paducah.

The graduate students typically have individual PCs that are used for their research and course work. The exchange of information and storage of information is accomplished using two separate computers (one on each campus); more recently file sharing software has started to be used. Research group papers, presentations, and theses are archived on the computer in Paducah.

Often it is not practical to use desktop sharing to view the output of large computer simulations that involve significant video imaging. In these cases the faculty adviser can transfer the simulation output to a local computer in Paducah to view the results. Situations can arise when the file size is large and impact the data transfer rate on the Paducah campus. In these cases data files are transferred after normal working hours, which can delay responsiveness on questions or problems that could be more easily solved if the faculty advisor was in the same location as the graduate student.

\section{Student Feedback}

Over the years the authors have discussed the distance mentoring with students that have completed their graduate programs. The consistent issue that is always mentioned is the advisor not being locally present impacts research productivity, particularly in the initial stages of their 
research program. The tendency is to wait until formal research meetings to discuss problems that are slowing research progress. Other comments have revolved around the distance communication technology that included learning how to use it, and problems arising during research meetings.

\section{Summary and Conclusions}

The distance advising of graduate students requires much pre-planning and flexibility on the faculty advisors' and students' part. Resources and time involved are factors that need to be carefully considered. At this time and in the present setting, computational projects are more easily accomplished than experimental projects. There are many problems that can occur with the distance communication efforts, which requires patience and flexibility by both the graduate student and the faculty advisor. Students that are comfortable with computers and are selfstarters tend to progress faster in a distance graduate student setting.

\section{References}

${ }^{1}$ Griffin, L., Walsh, D., Crockett, R., and Szlavik, R., 2008, “Action at Distance: A MS Degree Offered Through Distance Learning as a Vector to Student Enrichment and Industrial Interaction,” 2008 ASEE Annual Proceedings, 2008 ASEE Annual Conference \& Exposition.

${ }^{2}$ Biezad, D. and Tso, J., 2001, “Adapting Graduate Degree Programs to the Distance Learning Environment,” 2001 ASEE Annual Proceedings, 2001 ASEE Annual Conference \& Exposition.

${ }^{3}$ Hines, J.W., Miller, L.F., Pevey, R.E., Townsend, L.W., Upadhayaya, B.R., Dodds, J.L. and Jackson, R.H., 2002, "The Use of Information Technology in The University of Tennessee Nuclear Engineering Distance Education Program,” 2002ASEE Annual Proceedings, 2002 ASEE Annual Conference \& Exposition.

${ }^{4}$ Bumblauskas, D., 2009, “Online Distance Education: Hybrid Coursework \& Research Methods,” 2009 ASEE Midwest Section Conference Proceedings.

${ }^{5}$ Kassegne, S.K.., 2006, "Work in Progress: Lessons from Virtual Supervision of Engineering and Computer Science Graduate Students - Case of Addis Ababa University,” 2006 Frontiers in Education Conference Proceedings.

${ }^{6}$ Capece, V.R., Murphy, W.E., Lineberry, G.T., and Lykins, B., 2000, “Development of an Extended Campus Mechanical Engineering Program,” 2000 ASEE Annual Proceedings, 2000 ASEE Annual Conference \& Exposition. 